und Ergänzung: 1870 übernahm er die Bauleitung für die großzügige Restaurierung der Burg in Vajdahunyad (Hunedoara), trat von dieser Funktion aber 1874 zurück. 1877-1901 kam es unter seiner Ägide zu einer der größten Restaurierungsaktionen Ungarns, der des Doms von Kaschau (Košice), wobei S. eine gründl. Erneuerung der Bausubstanz und die Veränderung des Gewölbesystems vornahm. $\mathrm{Zu}$ S.s weiteren wichtigen Restaurierungsarbeiten zählen die Kirchen von Bartfeld (Bardejov, 1879-98) und Máriafalva (Mariasdorf, 1879-88), die Innerstädt. Pfarrkirche von Pest (1889-94) und die Kirche in Zipser Neudorf (Spišská Nová Ves). S., einer der bedeutendsten Vertreter der ung. historist. Architektur, wurde u. a. 1879 Ritter des Franz JosephOrdens, erhielt 1899 das österr.-ung. Ehrenzeichen für Kunst und Wiss., war Mitgl. der ersten unabhängigen ung. Organisation für Denkmalpflege (der 1872 gegr. Provisor. Komm. der Denkmale), ab 1894 Ehrenmitgl. des Royal Inst. of British Architects und $\mathrm{ab} 1898$ k. M. der Ung. Akad. der Wiss.

W.: s. u. Sisa, 2005.

L.: NFP, 1., Pester Lloyd, 1. (A.), 3. 9. 1902; M. Életr. Lex. (m. B.): Müvészeti Lex. I, II: Szinnyei; ThiemeBecker; K. Csányi, in: Müvészet, 1902, S. 334ff. (m. B.); J. Sisa, in: Mitt. der Ges. für vergleichende Kunstforschung in Wien 37, 1985, Nr. 3, S. Iff.; S. I. (1839-1902) épitész, müegyetemi tanár emlékezete, ed. A. Horváth, 1989; Lex. der Kunst 11, 1994; The Dictionary of Art 29, 1996; Az ország háza. Buda-pesti országháza-tervek 1784-1884. The House of the Nation. Parliament Plans for Buda-Pest 1784-1884, ed. E. Gábor - M. Verö, Budapest 2000, s. Reg. (Kat.); J. Sisa, S. I., 2005 (m. W.); ABK, Wien.

(J. Sisa)

Steindl (Staindl) Mat $(\mathrm{t})$ hias Paulus, Bischof. Geb. Wieden, NÖ (Wien), 24. 9. 1761; gest. Wien, 2. 5. 1828; röm.-kath. - Sohn eines Schuhmachers. Nach dem Theol.stud. in Wien wurde S. 1788 ebd. zum Priester geweiht, wirkte ab 1787 als Präfekt des Gen.seminars und nach dessen Auflösung ab 1793 als Vizedir., 1794-1806 als Regens des wiedererrichteten Wr. Priesterseminars. 1795 geriet er wegen „Pflichtwidrigkeit“ und demokrat. Gesinnung in seinem Amt in Konflikt mit der Regierung, wurde aber auf Intervention des Wr. Fürsterzbischofs Kardinal Christoph Anton Gf. Migazzi begnadigt. Ab 1802 war S. Prof. für bibl. Literatur und des neuen Bundes an der Wr. Univ.; 1803 Dr. theol., 1808-09 Dekan der theol. Fak., 1814-15 Rektor. 1806 nö. Reg.Rat, leitete er als solcher das Stud.- und geistl. Referat bis $\mathrm{zu}$ seinem Tod. S. fungierte auch als Beisitzer der Hofkomm. in dt. Schulsachen und war Zensor der theol. Bücher. 1814 Ehrenkanonikus des Metropolitankapitels zu St. Stephan, 1817 Domherr von St. Stephan, 1821 Domkustos. 1817 erfolgte seine Ernennung zum Gen.vikar der Wr. Erzdiözese und im selben Jahr zum Tit.bischof von Antinopolis und Wr. Weihbischof. 1823 wurde S. in seinem Amt als Gen.vikar bestätigt.

L.: Gatz, Bischöfe; Beitrr. zur Geschichte der nö. Statthalterei, 1896, S. 473; I. Fried, Das Metropolitankapitel $z u$ St. Stephan in Wien in seiner personellen Zusammensetzung ... 1722-1900, phil. Diss. Wien, 1952, S. 32, 36, 162f.; R. Ritzler - P. Sefrin, Hierarchia catholica medii et recentioris aevi ...7, 1968, S. 79, 242; L. Mathias, Das Wr. Priesterseminar ..., theol. Diss. Wien, 1975, S. $95 f f$. 100ff., 402, 433; Diözesanarchiv, Pfarrarchiv St. Stephan, beide Wien.

\section{(M. Sohn-Kronthaler)}

Steindler Olga, verehel. Ehrenhaft-S., Pädagogin und Physikerin. Geb. Wien, 28. 10. 1879; gest. ebd., 21. 12. 1933. - Nannte sich Ehrenhaft-S. Tochter eines Advokaten, ab 1908 mit dem Atomphysiker Felix Ehrenhaft (geb. Wien, 24. 4. 1879; gest. ebd., 4. 2. 1952) verehel. Nach Absolv. des Mädchengymn. des Wr. Ver. für erweiterte Frauenbildung und der Ablegung der Matura in Prag stud. S. ab 1899 Mathematik und Physik an der Univ. Wien; 1903 Dr. phil., gilt sie als erste prom. Physikerin der Univ. Wien. Im selben Jahr legte sie auch die Lehramtsprüfung für Mittelschulen ab. I. d. F. unterrichtete S. an einem Wr. Mädchengymn., befaßte sich daneben mit physikal. Fragestellungen aus dem Bereich der Optik und hielt Vorträge für die Vereinigung österr. Hochschuldoz. Athenäum. Ihr Engagement im Bereich der Frauenbildung und -förderung führte 1907 zur Gründung eines Mädchengymn. in Wien 2. Auf Grund ihres Strebens nach gediegener Berufsausbildung für begabte Mädchen aus ärmerem Haus gründete sie 1907 gem. mit Olly Schwarz einen Ver. für höhere kommerzielle Frauenbildung und die erste Handelsakad. für Mädchen in der Schönborngasse (Wien 8), deren Leitung sie als erste Schuldir., die in den Staatsdienst übernommen wurde, bekleidete. Bis zuletzt blieb durch ihren Ehemann eine lose Verbindung zur Physik bestehen. Als Ausz. für ihre Tätigkeit erhielt S. die Titel Reg.Rat und HR (1931) verliehen.

W.: Über die Temperaturcoeffizienten einiger Jodelemente, phil. Diss. Wien, 1903; Die Farbenempfindlichkeit des normalen und des farbenblinden Auges, 1906; Handelsschulen, in: Frauenbewegung, Frauenbildung und 